\title{
Fungos fitopatogênicos para biocontrole de Sagittaria montevidensis e seletividade para a cultura do arroz irrigado
}

\author{
André Pich Brunes( ${ }^{(1)}$, Sandro de Oliveira(1), Elisa Souza Lemes ${ }^{(1)}$, André Oliveira de Mendonça( ${ }^{(1)}$, \\ Letícia Winke Dias ${ }^{(1)}$, Dirceu Agostinetto( ${ }^{(2)}$ e Cândida Renata Jacobsen Farias ${ }^{(2)}$
}

\begin{abstract}
(1)Universidade Federal de Pelotas (Ufpel), Faculdade de Agronomia Eliseu Maciel (Faem), Departamento de Fitotecnia, Caixa Postal 354, CEP 96001-970 Pelotas, RS, Brasil. E-mail: beldar_brunes@msn.com, sandrofaem@yahoo.com.br, lemes.elisa@yahoo.com.br, andreh_mendonca@hotmail.com, leticiawinke@yahoo.com.br (2)Ufpel, Faem, Departamento de Fitossanidade, Caixa Postal 354, CEP 96001-970 Pelotas, RS, Brasil. E-mail: agostinetto@ig.com.br, candidajacobsen@bol.com.br
\end{abstract}

Resumo - O objetivo deste trabalho foi identificar, na micobiota de Sagittaria montevidensis, espécies de fungos fitopatogênicos com potencial bioherbicida, bem como avaliar sua seletividade para a cultura do arroz irrigado. Foram avaliadas as espécies de fungos Fusarium oxysporum e F. semitectum da micobiota de S. montevidensis e seis níveis de concentração de esporos $\left(0,1 \times 10^{3}, 1 \times 10^{4}, 1 \times 10^{5}, 1 \times 10^{6}\right.$ e $1 \times 10^{7}$ esporos $\left.\mathrm{mL}^{-1}\right)$, aplicados sobre plantas de $S$. montevidensis em estádio de uma folha sagitada e sobre plantas de arroz no estádio de desenvolvimento R4. Avaliou-se a progênie da cultura. Os isolados de F. oxysporum e F. semitectum apresentaram maior incidência sobre as plantas de S. montevidensis; porém, não foram eficazes no controle da espécie quando aplicados no estádio de plântula com uma folha sagitada. A aplicação de $F$. oxysporum e F. semitectum na fase de floração das plantas de arroz irrigado causa perdas no rendimento, redução no vigor das sementes produzidas e redução no comprimento radicular e da parte área.

Termos para indexação: Oryza sativa, Sagittaria montevidensis, biocontrole de plantas daninhas.

\section{Pathogenic fungi for biocontrol of Sagittaria montevidensis and selectivity for irrigated rice crop}

\begin{abstract}
The objective of this work was to identify, in the mycobiota of Sagittaria montevidensis, species of pathogenic fungi with potential to act as a bioherbicide, as well as to evaluate their selectivity for irrigated rice crop. The fungi species Fusarium oxysporum and F. semitectum of the mycobiota of S. montevidensis and six spore concentration levels $\left(0,1 \times 10^{3}, 1 \times 10^{4}, 1 \times 10^{5}, 1 \times 10^{6}\right.$, and $1 \times 10^{7}$ spores $\left.\mathrm{mL}^{-1}\right)$, applied on $S$. montevidensis plants in the stage of one sagittate leaf and on rice plants in the R4 growth stage, were assessed. The progeny of the culture was evaluated. Isolates of $F$. oxysporum and $F$. semitectum had greater impact on $S$. montevidensis plants; however, they were not effective in controlling the species when applied in the seedling stage with one sagittate leaf. The application of $F$. oxysporum and F. semitectum in the flowering stage of irrigated rice plants causes yield losses, reduction in the vigor of produced seeds, and reduction in root length and plant shoot.
\end{abstract}

Index terms: Oryza sativa, Sagittaria montevidensis, biocontrol of weeds.

\section{Introdução}

As plantas daninhas competem com a cultura do arroz (Oryza sativa L.) por luz, água e nutrientes, o que é um dos principais fatores limitantes da produtividade nas lavouras de arroz irrigado no Brasil (Arroz..., 2010). No entanto, essa interferência também pode ocorrer de forma indireta, uma vez que as plantas daninhas servem de hospedeiro secundário para pragas e patógenos (Radosevich et al., 2007).

Entre as espécies infestantes, destaca-se a Sagittaria montevidensis Cham. \& Schltdl., uma planta aquática que infesta grande parte dos canais de irrigação, bem como lavouras irrigadas no País, nos estados do Rio
Grande do Sul e Santa Catarina (Cassol et al., 2008). $O$ controle com uso de herbicidas de elevada ação residual apresenta maior eficiência, mas a aplicação de maneira indevida pode causar contaminações ambientais e levar à seleção de plantas resistentes.

A ocorrência de plantas de $S$. montevidensis com resistência cruzada a herbicidas inibidores da enzima acetolactato sintase (ALS) foi relatada 3 e 4 anos após a utilização do herbicida bensulfuron, em 1993 e 1994, na Califórnia, nos Estados Unidos, e em New South Wales, na Austrália, respectivamente (Heap, 2015; Merotto Junior et al., 2010). Em 2003, foram identificados biótipos resistentes de $S$. montevidensis em lavouras de arroz irrigado na China (Heap, 2015). 
No Brasil, atualmente, há registros de populações de S. montevidensis resistentes aos herbicidas inibidores da ALS em praticamente todos os municípios produtores de arroz irrigado em Santa Catarina, com carência de alternativas de controle eficientes (Concenço et al., 2007).

Para manejar essa resistência e encontrar práticas com menor impacto ambiental, buscam-se métodos de controle alternativo ao químico, como o controle biológico, que pode ser definido como a ação de organismos vivos para controlar ou reduzir a população de espécies de plantas indesejáveis. Nos últimos anos, esse método tem ganhado destaque como uma opção para controlar plantas daninhas da família Alismatacea, que inclui S. montevidensis (Soares \& Barreto, 2009; Lima et al., 2010).

A estratégia inundativa ou de bioherbicida preconiza a utilização de microrganismo de forma maciça sobre a população da planta daninha, para gerar rápido e alto nível de doença, com consequente morte ou supressão da espécie hospedeira (Charudattan, 1991). O sucesso do micoherbicida depende da produção abundante e durável do inóculo em cultura artificial, em que o patógeno deve ser geneticamente estável e específico para a espécie-alvo e não deve manifestar patogenicidade para a cultura de interesse, além de apresentar baixo custo de produção (Lima et al., 2010).

$\mathrm{O}$ objetivo deste trabalho foi identificar, na micobiota de Sagittaria montevidensis, espécies de fungos fitopatogênicos com potencial bioherbicida, bem como avaliar sua seletividade para a cultura do arroz irrigado.

\section{Material e Métodos}

O trabalho consistiu das seguintes etapas: levantamento das espécies de fungos patogênicos associados às plantas de $S$. montevidensis; isolamento dos fungos; avaliação do controle de $S$. montevidensis pelos isolados; e teste da seletividade dos isolados para a cultura do arroz.

Utilizou-se o delineamento experimental inteiramente casualizado, com cinco repetições. Os tratamentos foram: duas espécies de fungos (Fusarium oxysporum e $F$. semitectum) e seis níveis de concentração de esporos $\left(0,1 \times 10^{3}, 1 \times 10^{4}, 1 \times 10^{5}\right.$, $1 \times 10^{6}$ e $1 \times 10^{7}$ esporos $\mathrm{mL}^{-1}$ ), em arranjo fatorial $2 \times 6$. Os esporos foram aplicados no estádio em que as plantas apresentavam uma folha sagitada.
O levantamento de espécies de fungos fitopatogênicos associados a lesões de plantas de $S$. montevidensis foi realizado em lavouras de arroz irrigado em três municípios da região Sul do Estado do Rio Grande do Sul, na safra agrícola de 2011/2012. Os locais de coleta foram Pelotas, Arroio Grande e Santa Vitória do Palmar, que são os municípios que apresentam a segunda, a décima primeira e a décima sexta maior produtividade de arroz do Rio Grande do Sul, respectivamente (Safras, 2012). Foram selecionadas três lavouras, mapeadas com auxílio de GPS, e, em cada uma delas, três locais de coleta foram escolhidos ao acaso (Tabela 1).

Plantas com sintomas causados por fungos foram coletadas e plantadas individualmente em vasos de 8 L preenchidos com solo coletado de um horizonte A1 de um Planossolo Háplico eutrófico solódico (Santos et al., 2013); em seguida, foram transportadas ao laboratório de fungos fitopatogênicos da Universidade Federal de Pelotas (UFPel). As plantas com lesões foram desinfestadas superficialmente com hipoclorito de sódio a $1 \%$, submetidas à câmara úmida e acondicionadas em sala de crescimento durante 7 dias, com temperatura de $24^{\circ} \mathrm{C}$ e fotoperíodo de $12: 12$ horas luz:escuro, até esporulação. Após o período de incubação, os fungos foram classificados em gêneros. Para isso, prepararam-se lâminas para análise microscópica, e as características dos esporos (cor, formato e septação) e os tipos de esporóforos foram comparados com os descritos na literatura (Barnett \& Hunter, 1987).

Por estarem presentes em maior incidência nas amostras, fungos do gênero Fusarium foram classificados em espécie, tendo-se observado características macro e microscópicas das colônias. Para tanto, fragmentos das colônias puras foram repicados para o centro de uma placa de Petri, que continha meio de cultura batata-dextrose-ágar (BDA), e incubados em sala de crescimento $\left(25^{\circ} \mathrm{C}\right.$ e 12 horas luz por 14 dias). Para estudos das características microscópicas, foram utilizadas lâminas de microcultivo, observadas quanto à presença e à formação de macro e microconídios. As características visualizadas foram comparadas com as descritas na literatura (Nelson et al., 1983).

Para confirmar se os sintomas observados nas folhas foram desencadeados pelos patógenos inoculados, foram preparadas câmaras úmidas, com uso de caixas do tipo gerbox - cada uma continha duas folhas de papel 
mata-borrão umedecido com água destilada. No interior dessas caixas, foram colocados fragmentos das folhas lesionadas, para incubação em sala de crescimento $\left(25^{\circ} \mathrm{C}\right.$ e 12 horas luz por 7 dias). Em seguida, foram preparadas lâminas, para análise microscópica dos sinais do patógeno nas lesões, que foram comparadas com as estruturas inoculadas anteriormente. Os dados foram expressos em percentual, por meio da estatística descritiva.

A avaliação do nível de controle de $S$. montevidensis foi realizada em casa de vegetação e no Laboratório de Fungos Fitopatogênicos da UFPel. Para isso, foram coletadas plantas de $S$. montevidensis, com ausência de sintomas de infecção por patógenos, em estágio de plântula com três a quatro folhas lanceoladas,

Tabela 1. Locais de coleta de plantas de Sagittaria montevidensis em três municípios da região Sul do Rio Grande do Sul.

\begin{tabular}{|c|c|c|c|}
\hline \multirow[t]{2}{*}{ Lavoura } & \multirow{2}{*}{$\begin{array}{l}\text { Ponto de } \\
\text { coleta }\end{array}$} & \multicolumn{2}{|c|}{ Coordenadas geográficas } \\
\hline & & Latitude & Longitude \\
\hline & & \multicolumn{2}{|c|}{ Arroio Grande } \\
\hline & 1 & $-32,233873$ & $-53,050668$ \\
\hline \multirow[t]{3}{*}{ A } & 2 & $-32,235538$ & $-53,047969$ \\
\hline & 3 & $-32,238315$ & $-53,043354$ \\
\hline & 1 & $-32,296559$ & $-52,857952$ \\
\hline \multirow[t]{3}{*}{ B } & 2 & $-32,297469$ & $-52,857333$ \\
\hline & 3 & $-32,302948$ & $-52,880343$ \\
\hline & 1 & $-32,273930$ & $-52,906804$ \\
\hline \multirow[t]{4}{*}{$\mathrm{C}$} & 2 & $-32,278284$ & $-52,912075$ \\
\hline & 3 & $-32,284448$ & $-52,916591$ \\
\hline & & \multicolumn{2}{|c|}{ Santa Vitória do Palmar } \\
\hline & 1 & $-33,496170$ & $-53,402065$ \\
\hline \multirow[t]{3}{*}{ A } & 2 & $-33,500792$ & $-53,403213$ \\
\hline & 3 & $-33,523434$ & $-53,414976$ \\
\hline & 1 & $-33,637232$ & $-53,493301$ \\
\hline \multirow[t]{3}{*}{ B } & 2 & $-33,633542$ & $-53,488591$ \\
\hline & 3 & $-33,630501$ & $-53,484463$ \\
\hline & 1 & $-33,588147$ & $-53,445569$ \\
\hline \multirow[t]{4}{*}{$\mathrm{C}$} & 2 & $-33,583750$ & $-53,439468$ \\
\hline & 3 & $-33,576687$ & $-53,430936$ \\
\hline & & \multicolumn{2}{|c|}{ Pelotas } \\
\hline & 1 & $-31,807567$ & $-52,482595$ \\
\hline \multirow[t]{3}{*}{ A } & 2 & $-31,807520$ & $-52,481492$ \\
\hline & 3 & $-31,806793$ & $-52,481217$ \\
\hline & 1 & $-31,809076$ & $-52,464923$ \\
\hline \multirow[t]{3}{*}{ B } & 2 & $-31,809617$ & $-52,465209$ \\
\hline & 3 & $-31,809957$ & $-52,464450$ \\
\hline & 1 & $-31,812786$ & $-52,472415$ \\
\hline \multirow[t]{2}{*}{$\mathrm{C}$} & 2 & $-31,813949$ & $-52,472404$ \\
\hline & 3 & $-31,813983$ & $-52,473972$ \\
\hline
\end{tabular}

em área experimental de arroz irrigado no Centro de Herbologia da UFPel. As unidades experimentais constaram de copos de plástico de $500 \mathrm{~mL}$ com três plantas por copo, o que totalizou 60 copos preenchidos com solo oriundo da mesma área de coleta das plântulas. A patogenicidade dos fungos às plantas de $S$. montevidensis foi confirmada por meio dos postulados de Koch.

Colônias puras de fungos foram cultivadas em placas de Petri com meio de cultura BDA. As concentrações de esporos foram preparadas pelo método de raspagem da colônia pura, com adição de $50 \mathrm{~mL}$ de água destilada esterilizada e determinação da concentração dos esporos, por meio da quantificação em câmara de Neubauer, em microscópio óptico comum, com aumento de 400 vezes.

A aplicação foi realizada com aspersor manual, em volume de $6,0 \mathrm{~mL}$ por planta, o suficiente para obter o escorrimento superficial da solução de esporos sobre as folhas. Posteriormente, as unidades experimentais permaneceram em câmara úmida durante 21 dias. Ao final deste período, realizou-se a determinação da severidade da doença, pela escala descritiva de Horsfall-Barrett (Campbell \& Madden, 1990), tendose atribuído notas de acordo com a percentagem de área foliar lesionada: nota 0 , para folhas sadias; e nota 11 , para folhas mortas.

Os resultados obtidos foram analisados quanto à normalidade e à homocedasticidade, e, em seguida, foram submetidos à análise de variância. Quando significativas, as médias foram comparadas pelo teste $t$, para o fator espécie de fungo, e pela regressão polinomial, para o fator concentração de esporos, ambos a 5\% de probabilidade.

A seletividade dos isolados para a progênie da cultura do arroz irrigado foi avaliada em casa de vegetação e no Laboratório Didático de Análise de Sementes da UFPel. Utilizou-se o delineamento experimental inteiramente casualizado, com quatro repetições, e os tratamentos foram: duas espécies de fungos ( $F$. oxysporum e $F$. semitectum) e seis níveis de concentração de esporos $\left(0,1 \times 10^{3}, 1 \times 10^{4}, 1 \times 10^{5}, 1 \times 10^{6}\right.$ e $1 \times 10^{7}$ esporos $\left.\mathrm{mL}^{-1}\right)$, em arranjo fatorial. Os esporos foram aplicados no estádio de desenvolvimento R4 (Arroz..., 2010).

A cultivar utilizada foi a IRGA 424, tendo-se estabelecido quatro plantas por vaso com capacidade de $8 \mathrm{~kg}$, preenchido com solo. A calagem e a adubação 
com NPK foram realizadas 7 dias antes da semeadura, de acordo com os resultados da análise de solo. Após a semeadura, as unidades experimentais foram irrigadas diariamente, tendo-se mantido o solo próximo à capacidade de campo até o estabelecimento definitivo da lâmina de água aos 30 dias após a emergência.

A aplicação dos esporos foi realizada quando a cultura encontrava-se em estádio de floração (R4). Para isso, utilizou-se aspersor manual, em volume de $40 \mathrm{~mL} \mathrm{~m}^{-2}$, o suficiente para obter escorrimento superficial. No período de 24 horas antes e após a aplicação, as unidades experimentais permaneceram em câmara úmida, para manter as condições favoráveis para a penetração do patógeno.

A colheita foi realizada quando as plantas estavam nos estádios R8 e R9, o que caracteriza a maturidade fisiológica das sementes. Foram determinadas as variáveis: produção de sementes, por meio da pesagem das sementes colhidas ( $\mathrm{g}$ por planta), que tiveram a sua umidade corrigida para $13 \%$; sementes cheias por panícula, por meio da contagem manual de cinco panículas por repetição, que foram expressas em número de sementes cheias por panícula; e sementes vazias por panícula, pela contagem manual de cinco panículas por repetição, que foram expressas em número de sementes vazias por panícula.

A qualidade fisiológica das sementes foi avaliada pelos testes de: germinação, de acordo com as Regras para Análise de Sementes (Regras..., 2009); primeira contagem da germinação, aos 7 dias após a instalação do teste por ocasião da realização do teste de germinação; envelhecimento acelerado, como em Delouche \& Baskin (1973); frio (TF), de acordo com Cícero \& Vieira, (1994); e comprimento de parte aérea (CPA) e raiz (CR), seguindo a metodologia da Association of Official Seed Analysts (Seed..., 1983).

Para o teste de sanidade, foram utilizadas 16 repetições de 25 sementes por unidade experimental, as quais foram dispostas individualmente sobre duas folhas de papel mata-borrão umedecido, distanciadas cerca de 2,0 cm entre si, no interior de caixas do tipo gerbox, cobertas com tampas transparentes, para permitir a passagem de luz incidente. Os recipientes com as sementes foram dispostos sob lâmpadas de luz fluorescente branca, distanciados $40 \mathrm{~cm}$ entre si, em câmaras com fotoperíodo de 12 horas e temperatura de $20 \pm 2{ }^{\circ} \mathrm{C}$, durante 7 dias. Ao final deste período, as sementes foram examinadas individualmente com auxílio de estereomicroscópio com resolução de até $80 \mathrm{x}$, por meio da ocorrência de frutificações importantes para identificação de espécies fúngicas, e os resultados foram expressos em percentagem de ocorrência dos fungos com duas casas decimais (Regras..., 2009). As sementes que continham os fungos foram classificadas visualmente em quatro classes, de acordo com a área da semente infestada: classe 0 , sementes livres de infestação; classe 1 , até $1 / 3$ da semente coberta com estruturas do fungo; classe 2 , semente com $1 / 3$ até $2 / 3$ de sua superfície coberta com estruturas do fungo; e classe 3 , sementes com mais de $2 / 3$ de sua superfície coberta com estruturas do fungo.

Em seguida, realizou-se o teste de transmissibilidade com as sementes oriundas do teste de incubação. Em papel de filtro, semearam-se quatro repetições de 25 sementes para cada concentração e potencial avaliados, em caixas do tipo gerbox preenchidas com vermiculita previamente autoclavada a $120^{\circ} \mathrm{C}$, por $60 \mathrm{~min}$, e umedecida com $50 \%$ da capacidade de campo. As caixas foram colocadas em câmara de incubação com temperatura de $20^{\circ} \mathrm{C} \pm 2^{\circ} \mathrm{C}$ e fotoperíodo de 12 horas, durante 21 dias, de acordo com as Regras para Análises de Sementes (Regras..., 2009).

Os dados obtidos foram analisados quanto à normalidade eà homocedasticidade, e foram submetidos à análise de variância; quando significativas, as médias foram comparadas pelo teste $t$, para o fator espécie de fungo, e pela regressão polinomial, para o fator concentração de esporos, ambos a 5\% de probabilidade. Os dados referentes à sanidade das sementes foram analisados com a estatística descritiva.

\section{Resultados e Discussão}

Os fungos patogênicos, identificados a partir das observações das estruturas morfológicas das plantas de $S$. montevidensis, pertencem aos gêneros Fusarium spp., Botrytis sp. e Cercospora sp., associados às lesões nessas plantas. O gênero Fusarium, por estar associado a $100 \%$ das amostras, foi identificado a nível de espécie.

Verificou-se que todas as amostras estavam infectadas pelos fungos $F$. oxysporum e $F$. semitectum (Tabela 2), com predominância de $F$. oxysporum nas folhas e de $F$. semitectum no caule. Do total de amostras, 38\% também apresentaram infecção por Cercospora sp. e $31 \%$ por Botrytis sp. As lesões 
causadas pelo fungo Cercospora sp. distribuíram-se entre caules e folhas, enquanto as por Botrytis sp. foram observadas nos frutos e nos aquênios. No Município de Arroio Grande, $11 \%$ das amostras apresentaram infestação por Cercospora sp. e 22\% por Botrytis. Nas amostras provenientes do Município de Santa Vitória do Palmar, houve maior incidência de Cercospora sp. e Botrytis sp. do que nas demais localidades, de 100 e $67 \%$, respectivamente. Plantas coletadas no Município de Pelotas apresentaram somente infestação com as espécies de Fusarium.

Soares \& Barreto (2009) relataram as seguintes espécies de fungos fitopatogênicos em folhas de S. montevidensis: Pseudocercospora arthrospora, que causa necrose nas folhas, nos estados do Paraná, de Santa Catarina e do Rio de Janeiro; Plectosporium alismatis, em todos os estados da região Sul do Brasil, e nos estados do Rio de Janeiro e de Minas Gerais; Colletotrichum gloeosporioides, causadora da antracnose, nos estados do Rio de Janeiro, de Santa Catarina e do Rio Grande do Sul; Cercospora sagittariae, causadora de manchas necróticas nas folhas, em seis estados brasileiros; Cercospora apii, nos estados do Rio de Janeiro e de Minas Gerais; Botrytis cinerea, em folhas de $S$. montevidensis, somente em canais drenados e terras altas no Estado do Rio de Janeiro; e Alternaria alternata, causadora de

Tabela 2. Espécies de fungos fitopatogênicos ocorrentes em plantas de Sagittaria montevidensis coletadas em três locais (A, B e C) de três municípios da região Sul do Rio Grande do Sul.

\begin{tabular}{lcccc}
\hline Espécie & \multicolumn{3}{c}{ Incidência de fungos (\%) } & \multirow{2}{*}{ Média } \\
\cline { 2 - 4 } & $\mathrm{A}$ & $\mathrm{B}$ & $\mathrm{C}$ & \\
\cline { 2 - 4 } Fusarium oxysporum & 100 & 100 & 100 & 100 \\
Fusarium semitectum & 100 & 100 & 100 & 100 \\
Botrytis sp. & 33,3 & 0 & 33,3 & 22,2 \\
Cercospora sp. & 0 & 0 & 33,3 & 11,1 \\
\hline & \multicolumn{3}{c}{ Santa Vitória do Palmar } \\
Fusarium oxysporum & 100 & 100 & 100 & 100 \\
Fusarium semitectum & 100 & 100 & 100 & 100 \\
Botrytis sp. & 33,3 & 66,6 & 100 & 66,6 \\
Cercospora sp. & 100 & 100 & 100 & 100 \\
\hline & \multicolumn{4}{c}{ Pelotas } \\
Fusarium oxysporum & 100 & 100 & 100 & 100 \\
Fusarium semitectum & 100 & 100 & 100 & 100 \\
Botrytis sp. & 0 & 0 & 0 & 0 \\
Cercospora sp. & 0 & 0 & 0 & 0 \\
\hline
\end{tabular}

danos moderados nas folhas, apenas no Estado do Rio Grande do Sul. Porém, cabe destacar que não foram encontrados trabalhos que tenham relatado a presença de $F$. oxysporum e $F$. semitectum como infectantes dessa planta daninha.

Não houve interação entre os fatores espécie de Fusarium e concentração de esporos, nem efeito principal quanto ao nível de controle de plântulas de S. montevidensis (Tabela 3). Portanto, a aplicação das duas espécies de Fusarium até a concentração de $1 \times 10^{7}$ esporos $\mathrm{mL}^{-1}$ não foi efetiva no controle das plântulas de $S$. montevidensis, pois essa não diferiu do tratamento testemunha (concentração 0), quando as plântulas se encontravam no estádio de uma folha sagitada.

As lesões em plantas adultas durante a fase de prospecção dos fungos, confirmadas por meio dos postulados de Koch, originaram-se da infecção por $F$. oxysporum e F. semitectum. Assim, pode-se inferir que, durante a avaliação do nível de controle, as plantas de $S$. montevidensis não apresentaram suscetibilidade ao hospedeiro, pois, tanto a presença do patógeno quanto o ambiente favorável foram controlados no experimento. Além disso, o gênero Fusarium apresenta, em sua população, ampla variabilidade genética em relação à agressividade, o que foi verificado por Bueno et al. (2010) e Ferreira et al. (2015) em isolados de F. oxysporum f. sp. passiflorae e $F$. solani testados em maracujazeiro amarelo (Passiflora edulis f. flavicarpa).

Além dos danos diretos causados pela interferência direta das plantas daninhas nas lavouras de arroz, vale ressaltar que, durante os períodos de pousio, as plantas de $S$. montevidensis podem servir de hospedeiro secundário a patógenos associados à cultura, $\mathrm{o}$ que aumenta a fonte de inóculo inicial quando a

Tabela 3. Nível de controle de plântulas de Sagittaria montevidensis obtido por meio da aplicação de concentração de esporos de duas espécies de Fusarium.

\begin{tabular}{lcc}
\hline \multirow{2}{*}{$\begin{array}{l}\text { Concentração } \\
\text { (esporos mL }\end{array}$} & \multicolumn{2}{c}{ Nível de controle de Sagittaria montevidensis $(\%)$} \\
\cline { 2 - 3 } & Fusarium oxysporum & Fusarium semitectum \\
\hline $1 \times 10^{3}$ & $20,05^{\mathrm{ns}}$ & 45,94 \\
$1 \times 10^{4}$ & 5,83 & 29,09 \\
$1 \times 10^{5}$ & 4,03 & 38,91 \\
$1 \times 10^{6}$ & 1,21 & 47,94 \\
$1 \times 10^{7}$ & 2,23 & 26,11 \\
$\mathrm{CV}(\%)$ & 23,02 & 27,89 \\
\hline
\end{tabular}

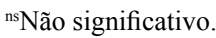


cultura estiver presente. Essa característica se torna particularmente importante por se tratar de espécies de Fusarium que apresentam grande gama de hospedeiros e que podem causar, desde murchas vasculares e podridões de colo e raízes até lesões foliares, de floração e frutificação (Mussi-Dias et al., 2012). O gênero é considerado um importante contaminante de cereais no campo, por causar apodrecimento de sementes e colmos (Almeida et al., 2005).

Constatou-se que a aplicação do concentrado de esporos nas plantas de arroz durante a floração não interferiu nas variáveis sementes vazias por panícula, primeira contagem da germinação e germinação (Tabela 4); portanto, a presença do patógeno não prejudicou a formação das sementes e não alterou sua habilidade germinativa. Também não houve influência dos tratamentos para envelhecimento acelerado, teste de frio e teste de transmissibilidade (Tabela 5). Assim, ambas as espécies de Fusarium não prejudicaram o vigor das sementes, e a presença dos fungos sobre elas não causou a doença durante o desenvolvimento da plântula, independentemente do nível de infestação inicial que continham.

Espécies de Fusarium podem se manifestar de diferentes formas, de acordo com a cultura existente, e seu ataque nem sempre causa a morte das plantas. Em arroz e outros cereais, a infecção com fungos do gênero Fusarium durante o período de floração pode ocasionar sintomas de ferrugem (Gautam \& Dill-Macky, 2012). Contudo, esses sintomas não foram observados no teste de transmissibilidade.

O comprimento da parte aérea e de raiz das plântulas, a produção de sementes por planta e de sementes cheias praticamente não apresentaram diferença entre as espécies de Fusarium aplicadas (Tabela 6). Em 71\% do total de comparações entre as duas espécies de fungos, não houve diferenças entre as espécies, enquanto em $21 \%, F$. oxysporum causou maiores prejuízos à cultura do arroz.

Quanto ao efeito da concentração de esporos, houve redução linear no comprimento da parte aérea das plântulas, de $0,16 \mathrm{~cm}$ por unidade de aumento exponencial, com a espécie $F$. oxysporum,

Tabela 4. Sementes vazias por planta, primeira contagem da germinação e germinação de sementes de plantas da cultivar IRGA 424 de arroz (Oryza sativa), submetidas à inoculação de duas espécies de Fusarium.

\begin{tabular}{|c|c|c|c|c|c|c|}
\hline \multirow{2}{*}{$\begin{array}{l}\text { Concentração } \\
\left(\text { esporos } \mathrm{mL}^{-1} \text { ) }\right.\end{array}$} & \multicolumn{2}{|c|}{ Sementes vazias por planta } & \multicolumn{2}{|c|}{ Primeira contagem da germinação (\%) } & \multicolumn{2}{|c|}{ Germinação (\%) } \\
\hline & $\begin{array}{c}\text { Fusarium } \\
\text { oxysporum }\end{array}$ & $\begin{array}{c}\text { Fusarium } \\
\text { semitectum }\end{array}$ & $\begin{array}{c}\text { Fusarium } \\
\text { oxysporum }\end{array}$ & $\begin{array}{c}\text { Fusarium } \\
\text { semitectum }\end{array}$ & $\begin{array}{c}\text { Fusarium } \\
\text { oxysporum }\end{array}$ & $\begin{array}{c}\text { Fusarium } \\
\text { semitectum }\end{array}$ \\
\hline 0 & $21^{\mathrm{ns}}$ & 21 & $86^{\text {ns }}$ & 86 & $96^{\text {ns }}$ & 96 \\
\hline $1 \times 10^{3}$ & 36 & 52 & 79 & 83 & 94 & 94 \\
\hline $1 \times 10^{4}$ & 33 & 36 & 80 & 77 & 92 & 93 \\
\hline $1 \times 10^{5}$ & 20 & 25 & 71 & 82 & 91 & 93 \\
\hline $1 \times 10^{6}$ & 39 & 48 & 78 & 78 & 91 & 92 \\
\hline $1 \times 10^{7}$ & 21 & 46 & 78 & 75 & 95 & 89 \\
\hline CV (\%) & \multicolumn{2}{|c|}{36,05} & \multicolumn{2}{|c|}{9,42} & \multicolumn{2}{|c|}{4,02} \\
\hline
\end{tabular}

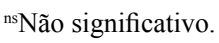

Tabela 5. Envelhecimento acelerado, teste de frio e teste de transmissibilidade em sementes de plantas da cultivar IRGA 424 de arroz (Oryza sativa), submetidas à inoculação de duas espécies de Fusarium.

\begin{tabular}{|c|c|c|c|c|c|c|}
\hline \multirow{2}{*}{$\begin{array}{l}\text { Concentração } \\
\left(\text { esporos } \mathrm{mL}^{-1} \text { ) }\right.\end{array}$} & \multicolumn{2}{|c|}{ Envelhecimento acelerado } & \multicolumn{2}{|c|}{ Teste de frio } & \multicolumn{2}{|c|}{ Teste de transmissibilidade (\%) } \\
\hline & $\begin{array}{l}\text { Fusarium } \\
\text { oxysporum }\end{array}$ & $\begin{array}{c}\text { Fusarium } \\
\text { semitectum }\end{array}$ & $\begin{array}{l}\text { Fusarium } \\
\text { oxysporum }\end{array}$ & $\begin{array}{c}\text { Fusarium } \\
\text { semitectum }\end{array}$ & $\begin{array}{l}\text { Fusarium } \\
\text { oxysporum }\end{array}$ & $\begin{array}{c}\text { Fusarium } \\
\text { semitectum }\end{array}$ \\
\hline 0 & $84^{\text {ns }}$ & 88 & $74^{\mathrm{ns}}$ & 74 & $0^{\text {ns }}$ & 0 \\
\hline $1 \times 10^{3}$ & 83 & 89 & 85 & 78 & 0 & 0 \\
\hline $1 \times 10^{4}$ & 87 & 89 & 72 & 76 & 0 & 0 \\
\hline $1 \times 10^{5}$ & 79 & 91 & 74 & 79 & 0 & 0 \\
\hline $1 \times 10^{6}$ & 92 & 91 & 77 & 77 & 0 & 0 \\
\hline $1 \times 10^{7}$ & 84 & 92 & 78 & 71 & 0 & 0 \\
\hline CV (\%) & \multicolumn{2}{|c|}{6,04} & \multicolumn{2}{|c|}{5,67} & & \\
\hline
\end{tabular}

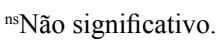


e comportamento quadrático negativo, com maior efeito sobre a parte aérea, na concentração de $10^{5,2}$ esporos $\mathrm{mL}^{-1}$, com $F$. semitectum (Figura $1 \mathrm{~A}$ ). $\mathrm{O}$ comprimento de raiz apresentou redução linear com a espécie $F$. oxysporum, em $0,99 \mathrm{~cm}$ de raiz por unidade de aumento na concentração de esporos; já com $F$. semitectum, houve comportamento quadrático negativo, com maior efeito sobre a raiz, na concentração de $10^{5,6}$ esporos $\mathrm{mL}^{-1}$ (Figura $1 \mathrm{~B}$ ).

Com ambas as espécies de fungos, o rendimento de sementes por planta reduziu-se linearmente com o aumento na concentração de esporos, em aproximadamente $0,20 \mathrm{~g}$ por planta por unidade de aumento na concentração de esporos (Figura 2 A). Em relação à variável sementes cheias por planta, houve redução de 3,29 por unidade de aumento na concentração de esporos de $F$. semitectum; entretanto, não foi constatado efeito significativo para essa variável, com F. oxysporum (Figura 2 B).

A percentagem de sementes de arroz classificadas na classe 1 aumentou com o incremento na concentração de esporos de $F$. oxysporum na solução aplicada sobre as plantas, em que a concentração de $10^{7}$ aumentou em $14,5 \%$ a percentagem de sementes infectadas nessa classe, em comparação à testemunha (Tabela 7). $\mathrm{O}$ número de sementes infestadas na classe 2 aumentou em $6 \%$, na maior concentração em relação à testemunha, e, na classe 3 , a concentração de $10^{5}$ foi superior às demais. Para a espécie $F$. semitectum, a concentração de $10^{3}$ apresentou maior número de sementes infestadas nas classes 1 e 2 , e houve pouca alteração no número de sementes infestadas na classe 3 .

Tabela 6. Comprimento de parte aérea (PA), comprimento de raiz de plântulas, rendimento de sementes por planta e sementes cheias por planta da cultivar IRGA 424 de arroz (Oryza sativa), submetida à inoculação de duas espécies de Fusarium $^{(1)}$.

\begin{tabular}{|c|c|c|c|c|c|c|c|c|}
\hline \multirow{2}{*}{$\begin{array}{l}\text { Concentração } \\
\text { (esporos } \mathrm{mL}^{-1} \text { ) }\end{array}$} & \multicolumn{2}{|c|}{ Comprimento de PA $(\mathrm{cm})$} & \multicolumn{2}{|c|}{ Comprimento de raiz $(\mathrm{cm})$} & \multicolumn{2}{|c|}{ Rend. sementes (g por planta) } & \multicolumn{2}{|c|}{ Sementes cheias } \\
\hline & $\begin{array}{l}\text { Fusarium } \\
\text { oxysporum }\end{array}$ & $\begin{array}{c}\text { Fusarium } \\
\text { semitectum }\end{array}$ & $\begin{array}{l}\text { Fusarium } \\
\text { oxysporum }\end{array}$ & $\begin{array}{c}\text { Fusarium } \\
\text { semitectum }\end{array}$ & $\begin{array}{l}\text { Fusarium } \\
\text { oxysporum }\end{array}$ & $\begin{array}{c}\text { Fusarium } \\
\text { semitectum }\end{array}$ & $\begin{array}{l}\text { Fusarium } \\
\text { oxysporum }\end{array}$ & $\begin{array}{c}\text { Fusarium } \\
\text { semitectum }\end{array}$ \\
\hline 0 (testemunha) & $5,7 \mathrm{a}$ & $5,7 \mathrm{a}$ & $16,0 \mathrm{a}$ & $16,0 \mathrm{a}$ & $3,2 \mathrm{a}$ & $3,2 \mathrm{a}$ & $85 a$ & $85 \mathrm{a}$ \\
\hline $10^{3}$ & $5,2 \mathrm{a}$ & $5,1 \mathrm{a}$ & $12,5 \mathrm{a}$ & $9,2 \mathrm{~b}$ & $2,5 b$ & $3,2 \mathrm{a}$ & $66 \mathrm{a}$ & $60 \mathrm{a}$ \\
\hline $10^{4}$ & $5,4 \mathrm{a}$ & $4,7 b$ & $12,3 \mathrm{a}$ & $9,8 \mathrm{~b}$ & $2,5 \mathrm{a}$ & $1,8 \mathrm{~b}$ & $80 \mathrm{a}$ & $70 \mathrm{a}$ \\
\hline $10^{5}$ & $4,6 \mathrm{a}$ & $4,9 a$ & $9,0 \mathrm{a}$ & $10,0 \mathrm{a}$ & $1,8 \mathrm{a}$ & $2,0 \mathrm{a}$ & $73 a$ & $66 a$ \\
\hline $10^{6}$ & $4,5 \mathrm{a}$ & $4,7 \mathrm{a}$ & $8,7 \mathrm{a}$ & $8,9 a$ & $1,7 \mathrm{a}$ & $2,0 \mathrm{a}$ & $89 a$ & $55 \mathrm{~b}$ \\
\hline $10^{7}$ & $4,5 \mathrm{~b}$ & $5,2 \mathrm{a}$ & $8,8 \mathrm{a}$ & $10,7 \mathrm{a}$ & $1,8 \mathrm{a}$ & $1,8 \mathrm{a}$ & $77 \mathrm{a}$ & $64 \mathrm{a}$ \\
\hline $\mathrm{CV}(\%)$ & \multicolumn{2}{|c|}{6,63} & \multicolumn{2}{|c|}{13,37} & \multicolumn{2}{|c|}{13,31} & \multicolumn{2}{|c|}{14,59} \\
\hline
\end{tabular}

${ }^{(1)}$ Médias seguidas de letras iguais, minúsculas nas linhas, não diferem pelo teste t, a 5\% de probabilidade.
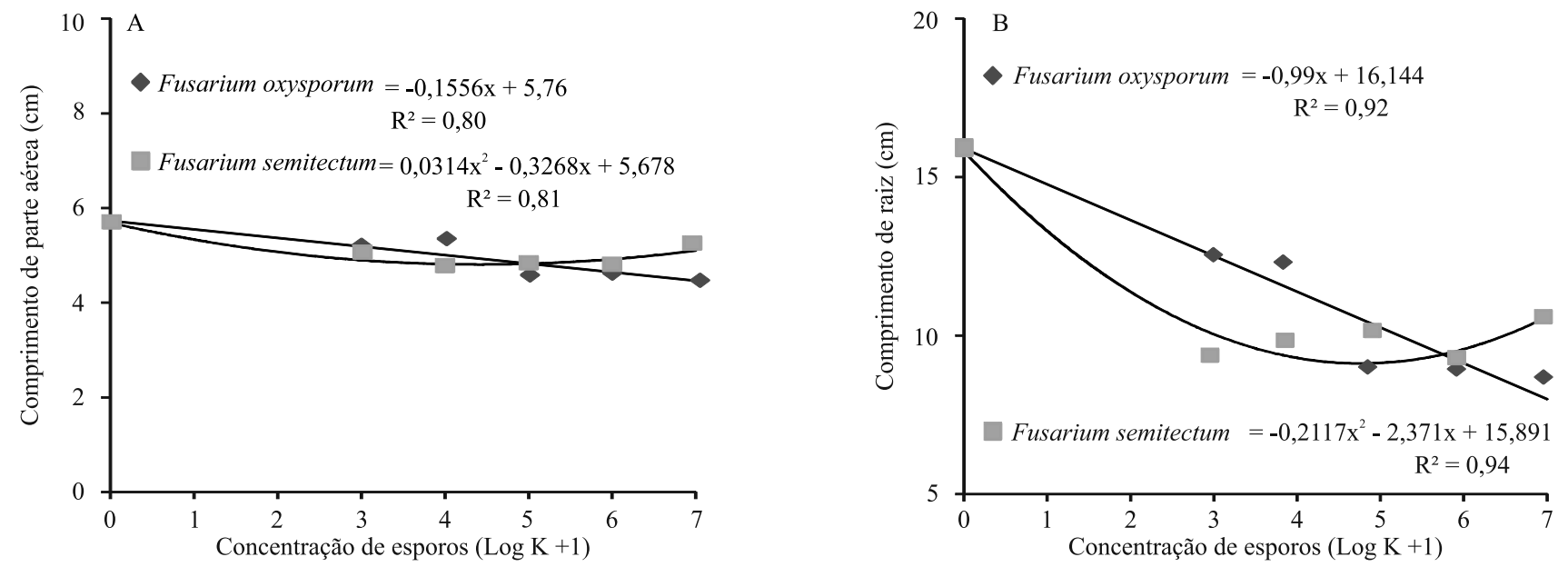

Figura 1. Comprimento de parte aérea (A) e comprimento de raiz (B) de plântulas da cultivar IRGA 424 de arroz (Oryza sativa), submetidas à solução com diferentes concentrações de esporos de Fusarium oxysporum e F. semitectum. 

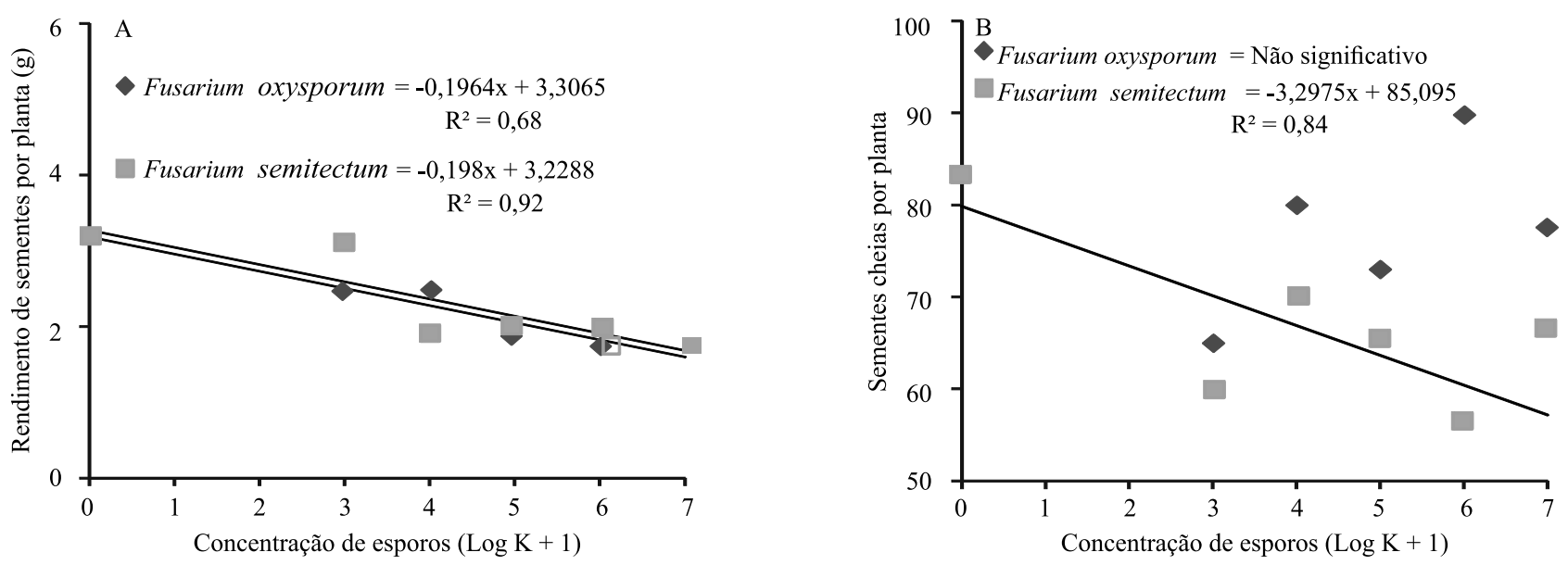

Figura 2. Rendimento de sementes por planta (A) e número de sementes cheias por planta (B) da cultivar IRGA 424 de arroz (Oryza sativa), submetida à solução com diferentes concentrações de esporos de Fusarium oxysporum e F. semitectum.

Tabela 7. Percentagem de sementes de plantas da cultivar IRGA 424 de arroz (Oryza sativa), submetidas à inoculação de duas espécies de fungos.

\begin{tabular}{|c|c|c|c|c|}
\hline \multirow{3}{*}{$\begin{array}{l}\text { Concentração } \\
\text { (esporos } \mathrm{mL}^{-1} \text { ) }\end{array}$} & Classe & Classe 1 & Classe 2 & Classe 3 \\
\hline & & 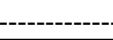 & & ---- \\
\hline & \multicolumn{4}{|c|}{ Fusarium oxysporum } \\
\hline 0 (testemunha) & 85,0 & 7,0 & 4,0 & 4,0 \\
\hline $10^{3}$ & 88,5 & 4,5 & 4,5 & 2,5 \\
\hline $10^{4}$ & 80,0 & 9,5 & 6,0 & 4,5 \\
\hline $10^{5}$ & 62,0 & 15,5 & 10,0 & 12,5 \\
\hline $10^{6}$ & 73,5 & 15,0 & 6,0 & 5,5 \\
\hline \multirow[t]{2}{*}{$10^{7}$} & 64,5 & 21,5 & 10,0 & 4,0 \\
\hline & \multicolumn{4}{|c|}{ Fusarium semitectum } \\
\hline 0 (testemunha) & 85,0 & 7,0 & 4,0 & 4,0 \\
\hline $10^{3}$ & 70,5 & 17,5 & 8,5 & 3,5 \\
\hline $10^{4}$ & 83,5 & 11,5 & 3,5 & 1,5 \\
\hline $10^{5}$ & 82,5 & 9,0 & 4,0 & 4,5 \\
\hline $10^{6}$ & 95,0 & 1,0 & 2,0 & 2,0 \\
\hline $10^{7}$ & 88,0 & 5,0 & 4,0 & 3,0 \\
\hline
\end{tabular}

\section{Conclusões}

1. Os fungos Fusarium oxysporum e F. semitectum apresentam maior incidência sobre as plantas de Sagittaria montevidensis ocorrentes em lavouras orizícolas da região Sul do Estado do Rio Grande do Sul.

2. Os isolados de F. oxysporum e F. semitectum não são efetivos no controle de $S$. montevidensis, quando aplicados no estádio fenológico de plântula com uma folha sagitada.
3. A aplicação de $F$. oxysporum e $F$. semitectum na fase de floração das plantas de arroz (Oryza sativa) irrigado causa perdas no rendimento, redução no vigor das sementes produzidas e redução no comprimento radicular e da parte aérea.

\section{Agradecimentos}

À Coordenação de Aperfeiçoamento de Pessoal de Nível Superior (Capes) e ao Conselho Nacional de Desenvolvimento Científico e Tecnológico (CNPq), pela concessão de bolsas.

\section{Referências}

ALMEIDA, A.P. de; SABINO, M.; FONSECA, H.; CORRÊA, B. Milho recém-colhido no Brasil: interação da microbiota fúngica, fatores abióticos e ocorrência de fumonisinas. Revista do Instituto Adolfo Lutz, v.64, p.1-9, 2005.

ARROZ irrigado: recomendações técnicas da pesquisa para o Sul do Brasil. Porto Alegre: Sociedade Sul-Brasileira de Arroz Irrigado, 2010.

BARNETT, H.L.; HUNTER, B.B. Illustrated genera of imperfect fungi. $4^{\text {th }}$ ed. New York: Macmillan, 1987. 218p.

BUENO, C.J.; FISCHER, I.H.; PARISI, M.C.M.; FURTADO, E.L. Comportamento do maracujazeiro amarelo, variedade Afruvec, ante uma população de Fusarium solani, agente causal da podridão do colo. Arquivos do Instituto Biológico, v.77, p.533-537, 2010.

CAMPBELL, C.L.; MADDEN, L.V. Introduction to plant disease epidemiology. New York: J. Wiley, 1990. 532p.

CASsol, B.; AGOSTINeTto, D.; MARIATH, J.E.A. Análise morfológica de Sagittaria montevidensis desenvolvida em 
diferentes condições de inundação. Planta Daninha, v.26, p.487-496, 2008. DOI: 10.1590/S0100-83582008000300003.

CHARUDATTAN, R. The mycoherbicide approach with plant pathogens. In: TEBEEST, D.O. (Ed.). Microbial control of weeds. New York: Chapman and Hall, 1991. p.24-57.

CÍCERO, S.M.; VIEIRA, R.D. Teste de frio. In: VIEIRA, R.D.; CARVALHO, N.M. de (Ed.). Testes de vigor em sementes. Jaboticabal: Funep, 1994. p.151-164.

CONCENÇO, G.; NOLDIN, J.A.; LOPES, N.F.; COMIOTTO, A. Aspectos da resistência de Sagittaria montevidensis ao herbicida pirazosulfuron-ethyl inibidor da ALS. Planta Daninha, v.25, p.187-194, 2007. DOI: 10.1590/S0100-83582007000100021.

DELOUCHE, J.C.; BASKIN, C.C. Accelerated aging techniques for predicting the relative storability of seed lots. Seed Science and Technology, v.1, p.427-452, 1973.

FERREIRA, R.B.; RODRIGUES, A.A.C.; MORAES, F.H.R.; SILVA, E.K.C.; NASCIMENTO, I. de O. Resíduos orgânicos no controle de Fusarium oxysporum f. sp. passiflorae em maracujazeiro amarelo (Passiflora edulis f. flavicarpa). Acta Biológica Colombiana, v.20, p.111-120, 2015. DOI: 10.15446/ abc.v20n3.44720.

GAUTAM, P.; DILL-MACKY, R. Free water can leach mycotoxins from Fusarium-infected wheat heads. Journal of Phytopathology, v.160, p.484-490, 2012. DOI: 10.1111/j.1439-0434.2012.01928.x.

HEAP, I. International survey of herbicide resistant weeds. Available at: $<$ http://www.weedscience.com $>$. Accessed on: 10 Jul. 2015.

LIMA, B.V.; SOARES, D.J.; BARRETO, R.W. Inoculum density of Plectosporium alismatis, a potential mycoherbicide, in relation to control of the aquatic weed Sagittaria montevidensis. Tropical Plant Pathology, v.35, p.236-240, 2010.
MEROTTO JUNIOR, A.; KUPAS, V.; NUNES, A.L.; GOULART, I.C.G. dos R. Isolamento do gene ALS e investigação do mecanismo de resistência a herbicidas em Sagittaria montevidensis. Ciência Rural, v.40, p.2381-2384, 2010. DOI: 10.1590/ S0103-84782010001100021.

MUSSI-DIAS, V.; ARAÚJO, A.C.O.; SILVEIRA, S.F.; ROCABADO, J.M.A.; ARAÚJO, K.L. Fungos endofíticos associados a plantas medicinais. Revista Brasileira de Plantas Medicinais, v.14, p.261-266, 2012. DOI: 10.1590/ S1516-05722012000200002.

NELSON, P.E.; TOUSSOUN, T.A.; MARASAS, W.F.O. Fusarium species: an illustrated manual for identification. University Park: Pennsylvania State University, 1983. 193p.

RADOSEVICH, S.R.; HOLT, J.S.; GHERSA, C.M. Ecology of weeds and invasive plants: relationship to agriculture and natural resource management. $3^{\text {rd }}$ ed. Hoboken: J. Wiley, 2007. DOI: $10.1002 / 9780470168943$

REGRAS para análise de sementes. Brasília: Ministério da Agricultura, Pecuária e Abastecimento, 2009. 395p.

SAFRAS. Porto Alegre: Instituto Rio Grandense do Arroz, [2012]. Disponível em: <http://www.irga.rs.gov.br/conteudo/4215/safras>. Acesso em: 26 jun. 2012.

SANTOS, H.G. dos; JACOMINE, P.K.T.; ANJOS, L.H.C. dos; OLIVEIRA, V.A. de; LUMBRERAS, J.F.; COELHO, M.R.; ALMEIDA, J.A. de; CUNHA, T.J.F.; OLIVEIRA, J.B. de. Sistema brasileiro de classificação de solos. 3.ed. Brasília: Embrapa, 2013. 353p.

SEED vigor testing handbook. [Washington]: Association of Official Seed Analysts, 1983. 93p.

SOARES, D.J.; BARRETO, R.W. Brazilian mycobiota of the aquatic weed Sagittaria montevidensis. Mycologia, v.101, p.401-416, 2009. DOI: 10.3852/08-063.

Recebido em 26 de janeiro de 2015 e aprovado em 7 de agosto de 2015

Pesq. agropec. bras., Brasília, v.50, n.10, p.886-894, out. 2015

DOI: 10.1590/S0100-204X2015001000004 